\title{
Monoacylglycerol lipase promotes progression of hepatocellular carcinoma via NF-KB-mediated epithelial-mesenchymal transition
}

Weiping Zhu ${ }^{1+}$, Yiming Zhao ${ }^{1 \dagger}$, Jiamin Zhou ${ }^{1 \dagger}$, Xin Wang $^{2 \dagger}$, Qi Pan ${ }^{1}$, Ning Zhang ${ }^{1}$, Longrong Wang ${ }^{1}$, Miao Wang ${ }^{1}$, Dihua Zhan', Zeyang Liu', Xigan $\mathrm{He}^{1}$, Dening $\mathrm{Ma}^{3}$, Shuang $\mathrm{Liu}^{3}$ and Lu Wang ${ }^{1 *}$

\begin{abstract}
Background: Monoacylglycerol lipase (MAGL), a critical lipolytic enzyme, has emerged as a key regulator of tumor progression, yet its biological function and clinical significance in hepatocellular carcinoma (HCC) is still unknown.

Methods: In this study, we used a tissue microarray containing samples from 170 HCC patients to evaluate the expression of MAGL and its correlation with other clinicopathologic characteristics. In addition, we investigated the regulating effects of MAGL on various HCC lines. Finally, we identified the NF-KB signaling pathway participated in MAGL-mediated epithelial-mesenchymal transition (EMT) using HCC cell lines with different metastatic potentials.

Results: The expression of MAGL was significantly higher in HCC tumors than in matched peritumor tissues. Specifically, high MAGL expression was found in tumors with larger tumor size, microvascular invasion, poor differentiation, or advanced TNM stage. In addition, the clinical prognosis for the MAGL ${ }^{\text {high }}$ group was markedly poorer than that for the MAGL ${ }^{\text {low }}$ group in the 1-, 3-, and 5-year overall survival times and recurrence rates of HCC patients. MAGL expression was an independent prognostic factor for both survival and recurrence after curative resection. Furthermore, the upregulation of MAGL in HCC cells promoted cell growth and invasiveness abilities, and accompanied by EMT. In contrast, downregulation of MAGL obviously inhibited these characteristics. Moreover, further investigations verified that MAGL facilitates HCC progression via NF-KB-mediated EMT process.
\end{abstract}

Conclusions: Our findings demonstrate MAGL could promote HCC progression by the induction of EMT and suggest a potential therapeutic target, as well as a biomarker for prognosis, in patients with HCC.

Keywords: MAGL, Hepatocellular carcinoma, NF-KB, EMT

\section{Background}

Hepatocellular carcinoma (HCC) is the fifth most common malignancy and the second leading cause of cancer-related deaths [1]. Tumor metastasis and recurrence is a critical contributor to the adverse prognosis $[2,3]$. Thus, a better understanding of biological characteristics in HCC becomes urgently needed. Epithelialmesenchymal transition (EMT) is a program playing a

\footnotetext{
*Correspondence: wang.lu99@hotmail.com

'Equal contributors

'Department of Hepatic Surgery, Fudan University Shanghai Cancer Center, Shanghai Medical College, Fudan University, Shanghai 200032, People's

Republic of China

Full list of author information is available at the end of the article
}

vital role in normal biological processes including embryogenesis, tissue remodeling, and wound healing $[4,5]$, which also correlated with the acquisition of increased aggressive and metastatic traits of tumor cells [6, 7]. To date, increasing EMT-related transcription factors, such as Snail, Twist, and Zeb1/2, are evidenced to be required in the EMT trigger in tumor progression [8-11]. Nevertheless, the molecular mechanisms for the upstream of these factors in HCC progression are not fully elucidated. Therefore, uncovering the specific regulation mechanisms of these factors may provide a new insight in therapeutic strategies of HCC $[12,13]$. 
Monoacylglycerol lipase (MAGL) is a lipolytic enzyme of lipid metabolism that catalyzes the conversion of monoacylglycerides to free fatty acids (FFA) and glycerol. MAGL plays a key role in several physiological processes including pain and nociperception through hydrolysis of the endocannabinoid 2-arachidonoylglycerol [14, 15]. Furthermore, MAGL also contributes to tumorigenesis and metastasis. Emerging studies have identified that expression of MAGL is elevated in many types of cancers, including melanoma, ovarian, and breast cancer [16]. MAGL could facilitate cancer cell proliferation and aggressiveness through the production of signaling lipids including monoacylglycerol (MAGs), FFA, and secondary lipid metabolites (especially LPA/PGE2). In addition, MAGL was found to be part of a gene expression signature that contains many markers of EMT $[17,18]$. Indeed, EMT-related markers are predictors for increased invasion, metastasis, and poor prognosis in some human tumor types [19]. However, little is known about the physiological role of MAGL in human HCC progression.

Here, we investigated the expression of MAGL in human HCCs and its clinical significance. In particular, we explored the roles of MAGL in the growth and invasiveness of HCC cells in vivo and in vitro. We also verified the signaling pathway by which MAGL promotes HCC cell aggressiveness. Our findings provided the underlying mechanism of MAGL in progression of HCC and suggesting MAGL as a potential therapeutic target for HCC.

\section{Results}

Expression of MAGL is upregulated in HCC patients and associated with recurrence

To investigate the effects of MAGL in HCC, we first detected MAGL expression in 27 tumor samples by immunohistochemical assay and found that MAGL expression was obviously elevated in HCC tissues compared with paired peritumor tissues (Fig. 1a). Consistently, western blot and qRT-PCR analysis of the indicated HCC patients demonstrated that the average expression of MAGL on both protein and mRNA levels were significantly higher in HCC tissues than peritumor tissues (Fig. 1b, c). Interestingly, immunohistochemical analysis for a large cohort of HCC samples $(n=170)$ showed that the expression of MAGL was significantly elevated in HCC patients with recurrence than those without recurrence $(P=0.001$; Fig. $1 \mathrm{~d})$, which indicated a potential role of MAGL in HCC progression.

\section{MAGL overexpression predicts a poor clinical outcome of} $\mathrm{HCC}$

To explore the clinical significance of MAGL expression in HCC, we further assessed the relationship between MAGL expression and the clinicopathologic characteristics in a TMA of 170 HCC patients (Table 1). Immunohistochemical analysis showed that the average intensity of MAGL expression in tumor was significantly higher than that in corresponding peritumor tissues. Notably, elevated MAGL expression was identified to be associated with larger tumor size $(P=0.048)$, microvascular invasion $(P=0.026)$, poor tumor differentiation $(P=0.012)$, and advanced TNM stage $(P=0.001)$. Whereas the other clinicopathologic characteristics, including age, gender, $\mathrm{HbsAg}, \mathrm{HCV}$, liver cirrhosis, alpha-fetoprotein, tumor number, or tumor encapsulation, showed no correlation with the expression level of MAGL in HCC.

In the present study, all $170 \mathrm{HCC}$ patients were dichotomized as MAGL ${ }^{\text {low }}$ expression $(n=77)$ and MAGL ${ }^{\text {high }}$ expression $(n=93)$, with MAGL ${ }^{\text {high }}$ expression accounting for $54.7 \%$ (93 of 170). Moreover, patients in the MAGL ${ }^{\text {high }}$ expression group exhibited shorter OS than those in the MAGL ${ }^{\text {low }}$ expression group ( $P=0.003$; Fig. 1e). Consistently, the $1-, 3-$, and 5 -year OS rates after surgery were much worse in the MAGL ${ }^{\text {high }}$ expression group than those in the MAGL ${ }^{\text {low }}$ expression group ( 66.7 vs. $80.5 \%, 32.5$ vs. $57.7 \%, 29.7$ vs. $47.8 \%$, respectively). In addition, the TTR in the MAGL ${ }^{\text {low }}$ expression group was significantly lower than that in the MAGL ${ }^{\text {high }}$ expression group $(P=0.001$; Fig. $1 \mathrm{f})$, and the $1-, 3-, 5$-year TTR rates were significantly higher in the MAGL $^{\text {high }}$ group than in the MAGL ${ }^{\text {low }}$ group (13.4 vs. $9.4 \%, 66.7$ vs. $44.6 \%, 87.4$ vs. $58.5 \%$, respectively). Univariate and multivariate analysis indicated that MAGL was an independent prognostic factor for both OS $(\mathrm{HR}=$ 1.628, $P<0.05)$ and TTR $(\mathrm{HR}=1.593, P<0.05$; Tables 2 and 3 ). Thus, these data clearly revealed that MAGL is a valuable predictive factor for clinical outcome of $\mathrm{HCC}$.

\section{MAGL enhances HCC cell growth and invasiveness in vivo and in vitro}

To investigate the exact biological role of MAGL in HCC, we evaluated MAGL expression in various HCC cell lines (HepG2, SMMC7721, Huh7, MHCC97L, $\mathrm{MHCC} 97 \mathrm{H}$, and HCCLM3) and one normal liver cell line (L0-2). Data showed that the protein and mRNA expression of MAGL were significantly upregulated in HCC cell lines compared to in L0-2 cells $(P<0.05$; Fig. 2a, b). And the expression of MAGL was enhanced in parallel with the increase of the metastatic potential of HCC cells, with the lowest level in HepG2 cells and the highest level in HCCLM3 cells. Then, MAGL expression in HepG2, a MAGL ${ }^{\text {low }}$ HCC cell line, was successfully upregulated (HepG2-MAGL). Meanwhile, in HCCLM3, a MAGL ${ }^{\text {high }}$ HCC cell line was stably downregulated (HCCLM3-shMAGL) (Fig. 2c, d). Our data showed that the growth of HepG2-MAGL cells in vivo was significantly increased $(3350.0 \pm 250.0$ vs. $2076.7 \pm$ 


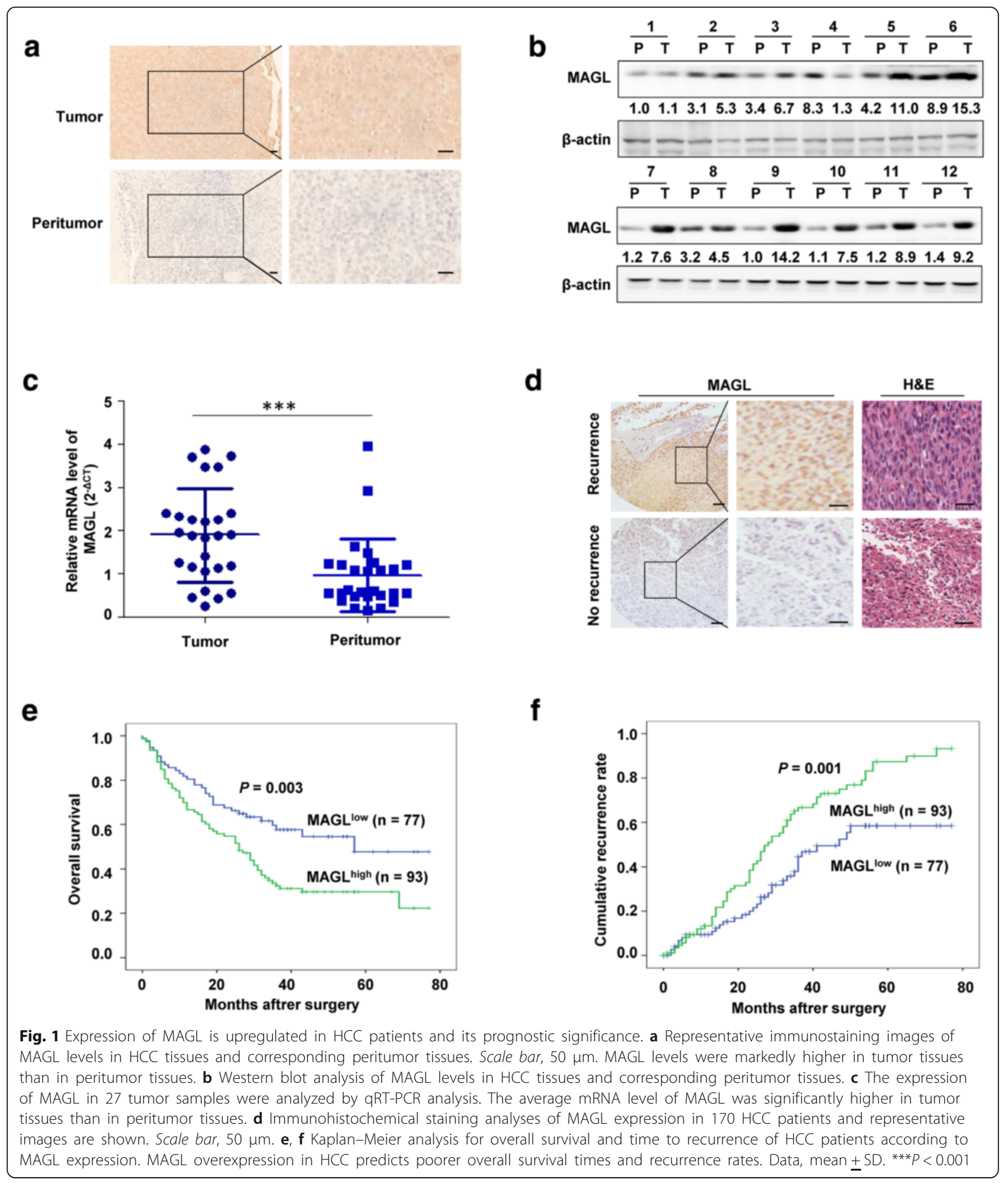

$302.7 \mathrm{~mm}^{3}, P<0.01$ ), whereas the growth of HCCLM3shMAGL cells was markedly restrained $(626.7 \pm 157.0$ vs. $\left.1756.7 \pm 172.1 \mathrm{~mm}^{3}, P<0.01\right)$, compared to their respective controls (HepG2-vector and HCCLM3-vector) (Fig. 2e). Moreover, the wound healing and transwell
Matrigel invasion assays demonstrated that upregulation of MAGL in HepG2 cells promoted its migratory and invasive capacities, while HCCLM3-shMAGL cells with decreased MAGL levels exhibited reduced motility and invasiveness, compared with their respective controls 
Table 1 Clinical characteristics of 170 HCC patients and correlation with MAGL staining

\begin{tabular}{|c|c|c|c|}
\hline \multirow[b]{2}{*}{ Variables } & \multicolumn{3}{|l|}{ MAGL staining } \\
\hline & Low $(n=77) n(\%)$ & High $(n=93) n(\%)$ & $P$ \\
\hline \multicolumn{4}{|l|}{ Gender } \\
\hline Male & $67(87.0)$ & $78(83.9)$ & \multirow[t]{2}{*}{0.565} \\
\hline Female & $10(13.0)$ & $15(16.1)$ & \\
\hline \multicolumn{4}{|l|}{ Age(years) } \\
\hline$\leq 50$ & $28(36.4)$ & 37 (39.8) & \multirow[t]{2}{*}{0.648} \\
\hline$>50$ & 49 (63.6) & $56(60.2)$ & \\
\hline \multicolumn{4}{|l|}{$\mathrm{HBsAg}$} \\
\hline Negative & $14(18.2)$ & $11(11.8)$ & \multirow[t]{2}{*}{0.244} \\
\hline Positive & $63(81.8)$ & $82(88.2)$ & \\
\hline \multicolumn{4}{|l|}{$\mathrm{HCV}$} \\
\hline Negative & $74(96.1)$ & $91(97.8)$ & \multirow[t]{2}{*}{0.659} \\
\hline Positive & $3(3.9)$ & $2(2.2)$ & \\
\hline \multicolumn{4}{|l|}{ Liver cirrhosis } \\
\hline No & $30(39.0)$ & $29(31.2)$ & \multirow[t]{2}{*}{0.289} \\
\hline Yes & $47(61.0)$ & $64(68.8)$ & \\
\hline \multicolumn{4}{|l|}{ AFP(ng/ml) } \\
\hline$\leq 20$ & $28(36.4)$ & $23(24.7)$ & \multirow[t]{2}{*}{0.099} \\
\hline$>20$ & 49 (63.6) & $70(75.3)$ & \\
\hline \multicolumn{4}{|l|}{ Tumor number } \\
\hline Single & $56(72.7)$ & $55(59.1)$ & \multirow[t]{2}{*}{0.064} \\
\hline Multiple & $21(27.3)$ & $38(40.9)$ & \\
\hline \multicolumn{4}{|l|}{ Tumor size(cm) } \\
\hline$\leq 5$ & $44(57.1)$ & $39(41.9)$ & \multirow[t]{2}{*}{0.048} \\
\hline$>5$ & $33(42.9)$ & $54(58.1)$ & \\
\hline \multicolumn{4}{|c|}{ Tumor encapsulation } \\
\hline Complete & $37(48.1)$ & $49(52.7)$ & \multirow[t]{2}{*}{0.547} \\
\hline Incomplete & $40(51.9)$ & $44(47.3)$ & \\
\hline \multicolumn{4}{|c|}{ Microvascular invasion } \\
\hline Absent & $48(62.3)$ & $42(45.2)$ & \multirow[t]{2}{*}{0.026} \\
\hline Present & $29(37.7)$ & $51(54.8)$ & \\
\hline \multicolumn{4}{|c|}{ Edmondson grade } \\
\hline$|-| \mid$ & $16(20.8)$ & $36(38.7)$ & \multirow[t]{2}{*}{0.012} \\
\hline III-IV & $61(79.2)$ & $57(61.3)$ & \\
\hline \multicolumn{4}{|l|}{ TNM stage } \\
\hline । & $18(23.4)$ & $5(5.4)$ & \multirow[t]{2}{*}{0.001} \\
\hline$\|-I\|$ & $59(76.6)$ & $88(94.6)$ & \\
\hline
\end{tabular}

$H B S A g$ hepatitis $B$ surface antigen, $H C V$ hepatitis $C$ virus, AFP alpha fetoprotein, TNM tumor node metastasis, MAGL monoacylglycerol lipase Italic numbers means $P<0.05$

(HepG2-vector and HCCLM3-vector) (Fig. 2f, g). Evidently, our results revealed that MAGL plays an important role in enhancing proliferative and invasive abilities of HCC cells in vivo and in vitro.

\section{MAGL promotes the progression of HCC by enhancing} EMT

To determine whether EMT contributes to the increased HCC cell growth and invasion induced by MAGL, we first identified the cellular morphology of HCC cell lines with different MAGL expression levels (HepG2-vector, HepG2-MAGL, HCCLM3-vector, and HCCLM3shMAGL). Results showed a significant difference in morphology of the indicated cell lines (Fig. 3a). In this study, HCC cells with higher MAGL levels (HepG2MAGL and HCCLM3-vector) exhibited a typical mesenchymal appearance which was more dispersed and presented a spindle-like morphology, while HepG2vector and HCCLM3-shMAGL cells showed a distinct epithelial morphology which took on a clustered and cobblestone-like appearance. These results suggested that MAGL might be closely correlated with EMT process in HCC. To confirm whether EMT is essential in the enhanced invasiveness of HCC cells mediated by MAGL, we explored EMT markers by western blot and qRT-PCR analysis in the indicated HCC cells. We found that E-cadherin expression was markedly downregulated in HepG2-MAGL and HCCLM3-vector cells, while mesenchymal markers, including $\mathrm{N}$-cadherin and the key EMT regulator Snail, were obviously upregulated compared with their respective controls (HepG2-vector and HCCLM3-shMAGL) (Fig. 3b-d and f). However, no significant differences were observed in other EMT markers such as vimentin and twist between groups with different MAGL levels (Fig. 3b, e, and g). Consistently, this phenomenon has also been observed in subcutaneous tumor samples by immunohistochemistry assay. Our data revealed an obvious reduction of E-cadherin expression in HepG2-MAGL group, with markedly upregulated expression of MAGL, N-cadherin, and Snail, compared to HepG2-vector group (Fig. 3h). Collectively, our data verified that MAGL overexpression might help HCC cells acquire EMT-like biochemical traits, which may contribute to MAGL-induced HCC cell growth and invasiveness.

\section{MAGL activated the NF-KB signal pathway in HCC cells}

It is increasingly appreciated that NF- $\mathrm{kB}$ signaling pathway plays a vital role in the tumor EMT process [20-22]. To uncover how MAGL affects the process of EMT, we assessed the activity of EMT-related molecules by western blot analysis in HCC cells. We found that the expression of NF- $\mathrm{KB}$ p65 was markedly increased in HepG2-MAGL cells but significantly reduced in HCCLM3-shMAGL cells compared to their respective controls (Fig. 4a, b), suggesting that NF- $\mathrm{kB}$ signaling might be responsible for MAGL-regulated HCC progression. To identify this hypothesis, we treated HepG2MAGL cells with MAGL-inhibitor JZL184 for various 
Table 2 Univariate analyses of factors associated with OS and TR

\begin{tabular}{|c|c|c|c|c|}
\hline \multirow[b]{2}{*}{ Variables $^{a}$} & \multicolumn{2}{|l|}{ OS } & \multicolumn{2}{|l|}{$T \mathrm{TR}$} \\
\hline & $\overline{\mathrm{HR}}(95 \% \mathrm{Cl})$ & $P$ & $\overline{\mathrm{HR}}(95 \% \mathrm{Cl})$ & $P$ \\
\hline Gender (male vs. female) & $1.375(0.751-2.518)$ & 0.302 & $1.072(0.605-1.898)$ & 0.811 \\
\hline Age ( $\leq 50$ vs. $>50$ years) & $0.863(0.577-1.289)$ & 0.471 & $1.140(0.748-1.738)$ & 0.542 \\
\hline HBsAg (negative vs. positive) & $1.444(0.788-2.646)$ & 0.234 & $1.833(0.974-3.449)$ & 0.061 \\
\hline HCV (negative vs. positive) & $1.157(0.365-3.669)$ & 0.805 & $0.612(0.150-2.503)$ & 0.494 \\
\hline Liver cirrhosis (no vs. yes) & $1.337(0.865-2.067)$ & 0.192 & $1.476(0.947-2.299)$ & 0.085 \\
\hline $\operatorname{AFP}(\leq 20$ vs. $>20 \mathrm{ng} / \mathrm{ml})$ & $1.408(0.893-2.219)$ & 0.140 & $1.005(0.650-1.553)$ & 0.983 \\
\hline Tumor number (single vs. multiple) & $1.731(1.160-2.581)$ & 0.007 & $1.877(1.247-2.826)$ & 0.003 \\
\hline Tumor size ( $\leq 5$ vs. $>5 \mathrm{~cm})$ & $2.211(1.461-3.345)$ & $<0.001$ & $1.936(1.278-2.934)$ & 0.002 \\
\hline Tumor encapsulation (complete vs. incomplete) & $1.566(1.049-2.338)$ & 0.028 & $1.116(0.744-1.676)$ & 0.595 \\
\hline Microvascular invasion (absent vs. present) & $1.602(1.074-2.389)$ & 0.021 & $1.556(1.033-2.345)$ & 0.035 \\
\hline Edmondson grade (I-II vs. III-IV) & $1.401(0.898-2.184)$ & 0.137 & $1.282(0.826-1.990)$ & 0.268 \\
\hline TNM stage (I vs. II-III) & $2.117(1.026-4.369)$ & 0.042 & $3.260(1.423-7.468)$ & 0.005 \\
\hline MAGL (low vs. high) & $1.856(1.220-2.823)$ & 0.004 & $2.040(1.331-3.128)$ & 0.001 \\
\hline
\end{tabular}

OS overall survival, $T R R$ time to recurrence, $H R$ hazard ratio, $C l$ confidence interval, $H B s A g$ hepatitis $\mathrm{B}$ surface antigen, $H C V$ hepatitis $C$ virus, $A F P$ alpha fetoprotein, TNM tumor node metastasis, MAGL monoacylglycerol lipase

${ }^{a}$ Variables were analyzed by Cox proportional hazards regression model

Italic numbers indicates that the variables might be associated with OS or TTR were subjected to the multivariate Cox analysis with 0.2 level for entry into the model

time periods and found the total protein expression of NF- $\mathrm{KB}$ p65 was downregulated in a time-dependent manner (Fig. 4c). Consistently, the expression of phosphorylated NF- $\mathrm{kB}$ p65 was also reduced in a timedependent manner when treated with JZL184 (Fig. 4d), suggesting that MAGL could affect the activation of NF$\kappa B$ signaling in HCC cells. Furthermore, our data showed that the level of NF- $\mathrm{kB}$ p 65 protein in the nucleus was detected to be downregulated in a timedependent manner, whereas this phenomenon was not observed in cytoplasm (Fig. 4e, f), suggesting that MAGL-inhibitor JZL184 could inhibit the translocation of NF- $\mathrm{kB}$ p65 protein into the nucleus, thus decreased the total expression level of NF- $\mathrm{B}$ p 65 . Evidently, our results clearly displayed that MAGL-inhibitor JZL184 could inhibit upregulation, phosphorylation, and nuclear translocation of NF-kB p65 in HCC cells, which means that MAGL overexpression could promote the activity of NF-kB p65 in HCC cells.

\section{MAGL facilitates EMT via the NF-KB signaling pathway}

To identify whether NF- $\kappa B$ pathway participated in the effects of MAGL on HCC cells, we blockaded the activation of NF- $\mathrm{kB}$ p65 using NF- $\mathrm{kB}$ p65-shRNA in HepG2-MAGL cells $(P<0.001$; Fig. 5 a, b). As expected, we found that the increased expression of

Table 3 Multivariate analyses of factors associated with OS and TTR

\begin{tabular}{|c|c|c|c|c|}
\hline \multirow[b]{2}{*}{ Variables $^{\mathrm{a}}$} & \multicolumn{2}{|l|}{ OS } & \multicolumn{2}{|l|}{ TTR } \\
\hline & $\mathrm{HR}(95 \% \mathrm{Cl})$ & $P$ & $\mathrm{HR}(95 \% \mathrm{Cl})$ & $P$ \\
\hline HBsAg (negative vs. positive) & & NA & $1.342(0.700-2.573)$ & 0.377 \\
\hline Liver cirrhosis (no vs. yes) & $1.278(0.795-2.053)$ & 0.311 & $1.356(0.855-2.149)$ & 0.195 \\
\hline AFP ( $\leq 20$ vs. $>20 \mathrm{ng} / \mathrm{ml})$ & $1.487(0.915-2.418)$ & 0.110 & & NA \\
\hline Tumor number (single vs. multiple) & $1.642(1.063-2.534)$ & 0.025 & $1.671(1.082-2.582)$ & 0.021 \\
\hline Tumor size ( $\leq 5$ vs. $>5 \mathrm{~cm}$ ) & $2.712(1.447-5.083)$ & 0.002 & $1.874(1.009-3.481)$ & 0.047 \\
\hline Tumor encapsulation (complete vs. incomplete) & $1.504(0.988-2.289)$ & 0.057 & & NA \\
\hline Microvascular invasion (absent vs. present) & $0.711(0.385-1.315)$ & 0.277 & $0.775(0.419-1.436)$ & 0.418 \\
\hline Edmondson grade (I-II vs. III-IV) & $1.574(0.989-2.504)$ & 0.056 & & NA \\
\hline TNM stage (| vs. ||-||I) & $1.023(0.444-2.358)$ & 0.957 & $1.726(0.687-4.340)$ & 0.246 \\
\hline MAGL (low vs. high) & $1.628(1.020-2.597)$ & 0.041 & $1.593(1.011-2.510)$ & 0.045 \\
\hline
\end{tabular}

OS overall survival, $T R R$ time to recurrence, $H R$ hazard ratio, $C l$ confidence interval, $H B s A g$ hepatitis B surface antigen, AFP alpha fetoprotein, TNM tumor node metastasis, MAGL monoacylglycerol lipase, NA not adopted

${ }^{a}$ Variables were adopted for their prognostic significance by multivariate analysis using the Cox proportional hazards regression model

Italic numbers means $P<0.05$ 
a

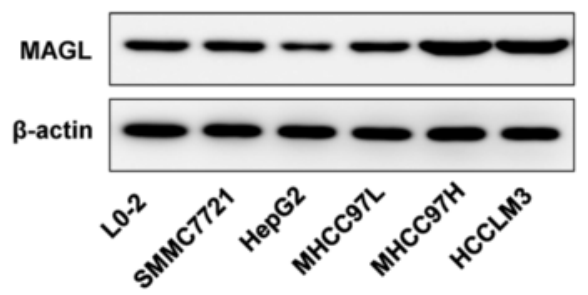

C

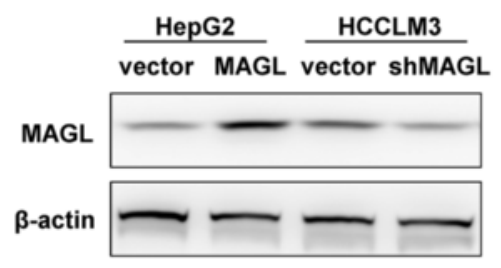

e
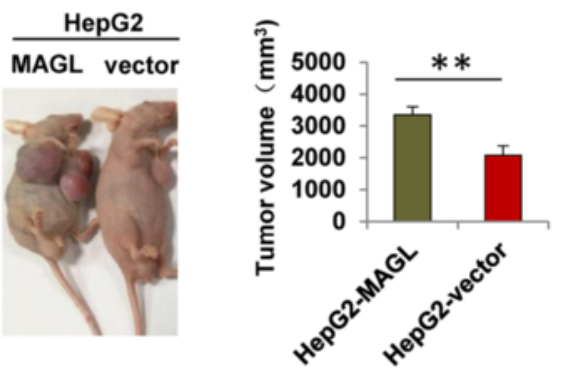

f

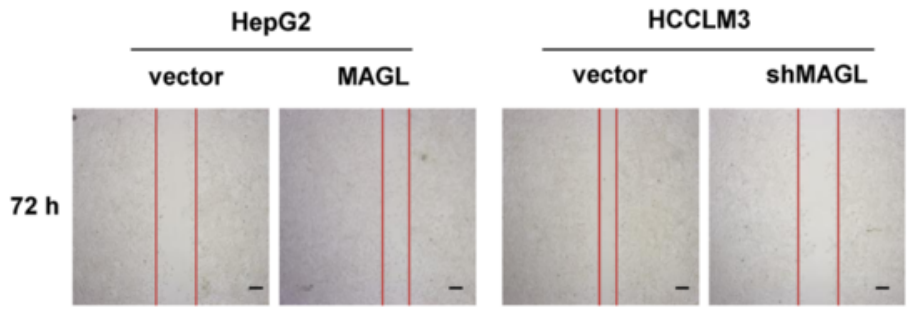

g

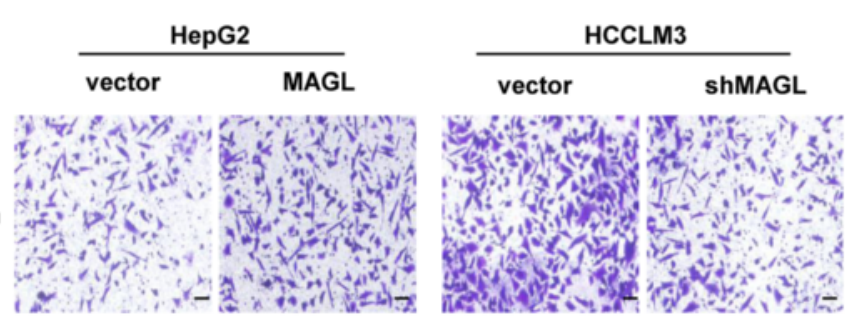

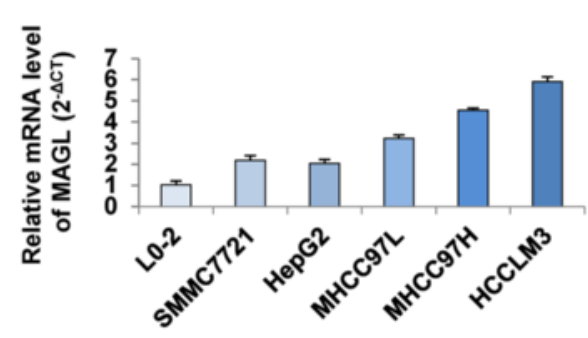

d
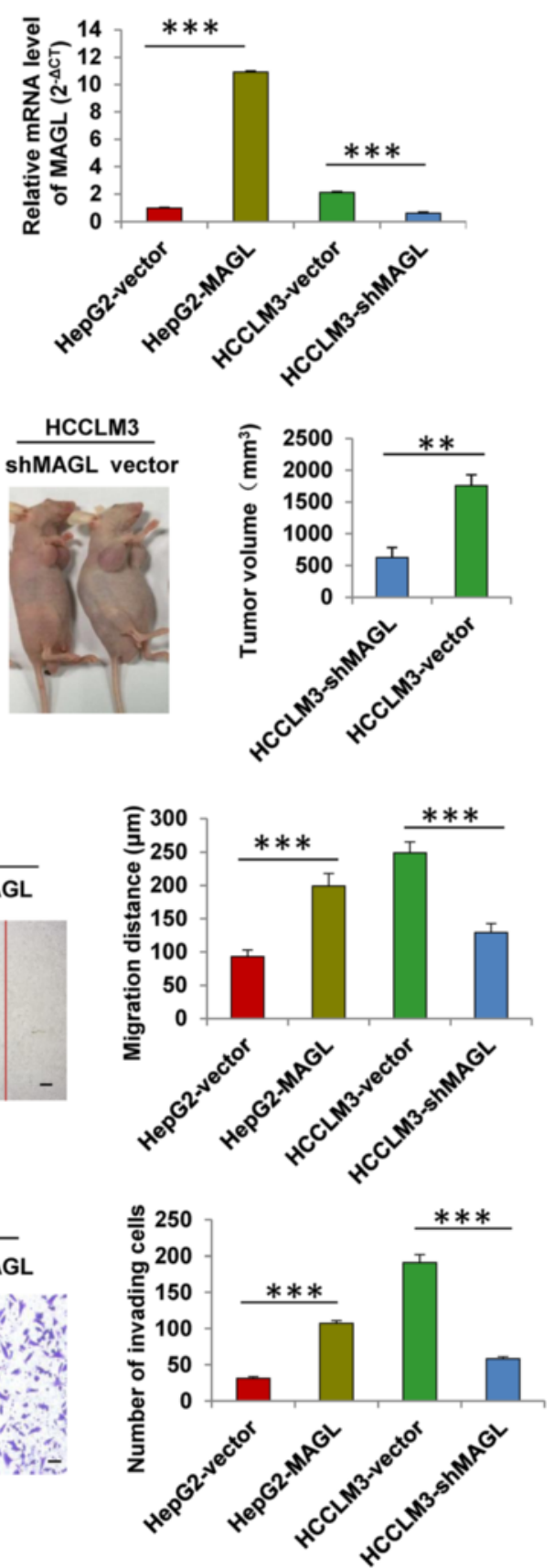

Fig. 2 (See legend on next page.) 
(See figure on previous page.)

Fig. 2 MAGL enhances HCC cell growth and invasiveness in vivo and in vitro. $\mathbf{a}$, $\mathbf{b}$ The protein and mRNA levels of MAGL in different HCC cell lines (HepG2, SMMC7721, Huh7, MHCC97L, MHCC97H, and HCCLM3) and one normal liver cell line (L0-2). c, d Western blot and qRT-PCR analysis showed the protein and mRNA expression of MAGL in HCC cells (HepG2-vector, HepG2-MAGL, HCCLM3-vector, and HCCLM3-shMAGL). e MAGL overexpression promoted HCC progression in vivo. Xenograft model of HCC in nude mice were established as described in the "Methods" section. The tumor volumes of subcutaneous tumors between the experiment and control groups exhibited significant differences. $\mathbf{f}$ The motility of HCC cells was detected by scratch wound assay, and statistics are shown with a bar graph. $\mathbf{g}$ The invasion ability of HCC cells was measured by transwell Matrigel invasion assay, and statistics are shown with a bar graph. Data, mean \pm SD. ${ }^{*} P<0.01$ and ${ }^{* *} P<0.001$

Snail, a key EMT regulator, could markedly be reversed at both protein and mRNA levels by NF- $\mathrm{kB}$ p65-shRNA treatment $(P<0.01$; Fig. 5a, c), while the enhanced expression levels of MAGL displayed no obvious changes (Fig. 5a, d). Furthermore, the wound healing and transwell Matrigel invasion assays showed that downregulation of NF-kB p65 in HepG2 cells with high MAGL expression could significantly inhibited MAGL-induced motility and invasiveness of HCC cells $(P<0.01$; Fig. 5e, f). Collectively, these results suggested that NF- $\mathrm{KB}$ pathway was involved in MAGLmediated EMT and contributed to the effects of HCC cells induced by MAGL.

\section{Discussion}

Alterations in lipid metabolism for cancer cells are increasingly being recognized. Cancer cells require fatty acids for energy storage, membrane proliferation, and generation of signaling molecules [23]. However, less is known about the metabolic pathway that confers aggressive properties, including high migratory and invasive abilities, on malignant cancers. The present study demonstrated that MAGL is distinctly upregulated and plays a positive role in HCC progression, which might represent a new link between the metabolic signature and tumor progression.

In this study, we used a large cohort of HCC samples to show that MAGL is expressed higher in HCC tissues than in peritumor tissues, and the MAGL expression was significantly associated with larger tumor size, microvascular invasion, tumor differentiation, and TNM stage. These observations were in accordance with previous reports in other malignancies such as prostate and colorectal cancer [17, 24, 25]. Furthermore, our survival analysis indicated that HCC patients with high expression of MAGL generally had even worse prognosis than those with low expression. MAGL expression was proved to be an independent prognostic factor for both recurrence and survival after curative resection. Our findings strongly imply MAGL as a marker for HCC aggressiveness and is predictive for prognosis of HCC.

Meanwhile, we found that upregulation of MAGL could promote in vivo growth and in vitro invasiveness of HCC cells, and this process was accompanied with EMT. EMT is a program that endows tumor cells with stem-like properties, including self-renewal, enhanced survival, and anchorage-independent growth [26]. After undergoing EMT program, epithelial tumor cells could acquire enhanced invasive and metastatic traits, which was associated with high-grade malignancy. In this study, the morphological characteristics in HCC cells with MAGL overexpression transformed from epithelial to mesenchymal, and the mesenchymal markers were remarkably upregulated while the epithelial markers were significantly decreased. In contrast, HCC cells with low MAGL expression exhibited opposite features, which suggested that MAGL could enable $\mathrm{HCC}$ cells to acquire mesenchymal-like traits, and thus promote HCC aggressiveness. These effects have previously been reported in other tumor cell lines [27]. Our findings further confirmed the effects. Taken together, our study demonstrated that MAGL could promote HCC cell aggressiveness through, at least partially, induction of EMT.

To date, multiple signaling pathways have been evidenced to be involved in EMT process, including NF$\kappa \mathrm{B}$, Hedgehog signaling, MAPKs, and so on. In this study, we verified that the activation of NF-kB p65 in HCC cells could be modulated by MAGL-inhibitor JZL184. Furthermore, MAGL-induced EMT in HCC cells was found to be carried out by the upregulation of Snail (Fig. 3), which depended on activation of NF-kB signaling (Fig. 5). Transcription factor Snail, which has been implicated in NF- $\mathrm{kB}$ - regulated EMT process [22], was evidenced to be one of the most important regulators for E-cadherin regulation $[9,10]$. Thus, upregulation of MAGL in HCC cells enhanced Snail activity through the activation of NF- $\mathrm{kB}$ signaling, which resulted in the downregulation of E-cadherin and further triggered subsequent EMT process.

\section{Conclusions}

In summary, we revealed a novel role for MAGL in the regulation of EMT via NF- $\mathrm{kB}$ pathway in HCC. Overexpression of MAGL in HCC is a potential biomarker of aggressive tumors and poor patient prognosis. Although further clinical trials are needed to assess its safety and effectiveness, our findings suggest that MAGL may be an attractive therapeutic target for HCC. 


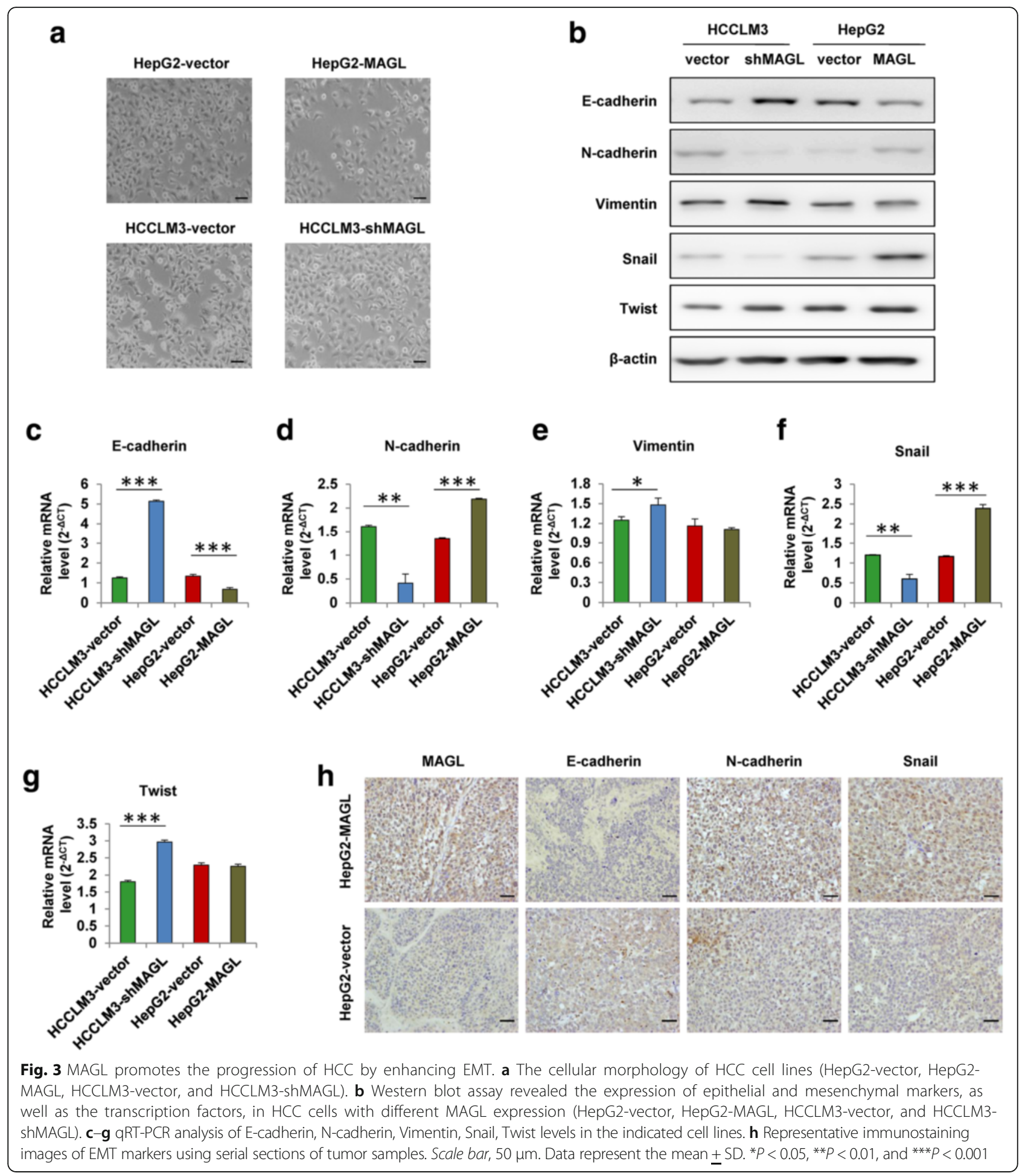

\section{Methods}

\section{Patients and specimens}

Tumor specimens $(n=27)$ were randomly collected from HCC patients who received curative resection at Fudan University Shanghai Cancer Center (Shanghai, People's Republic of China). A total of 170 patients who underwent curative resection for primary HCC from 2005 to 2011 in the Liver Cancer Institute, Zhong Shan hospital, Fudan University (Shanghai, People's Republic of China) were randomly enrolled. The detailed clinicopathological characteristics of these patients are presented in Table 1. 


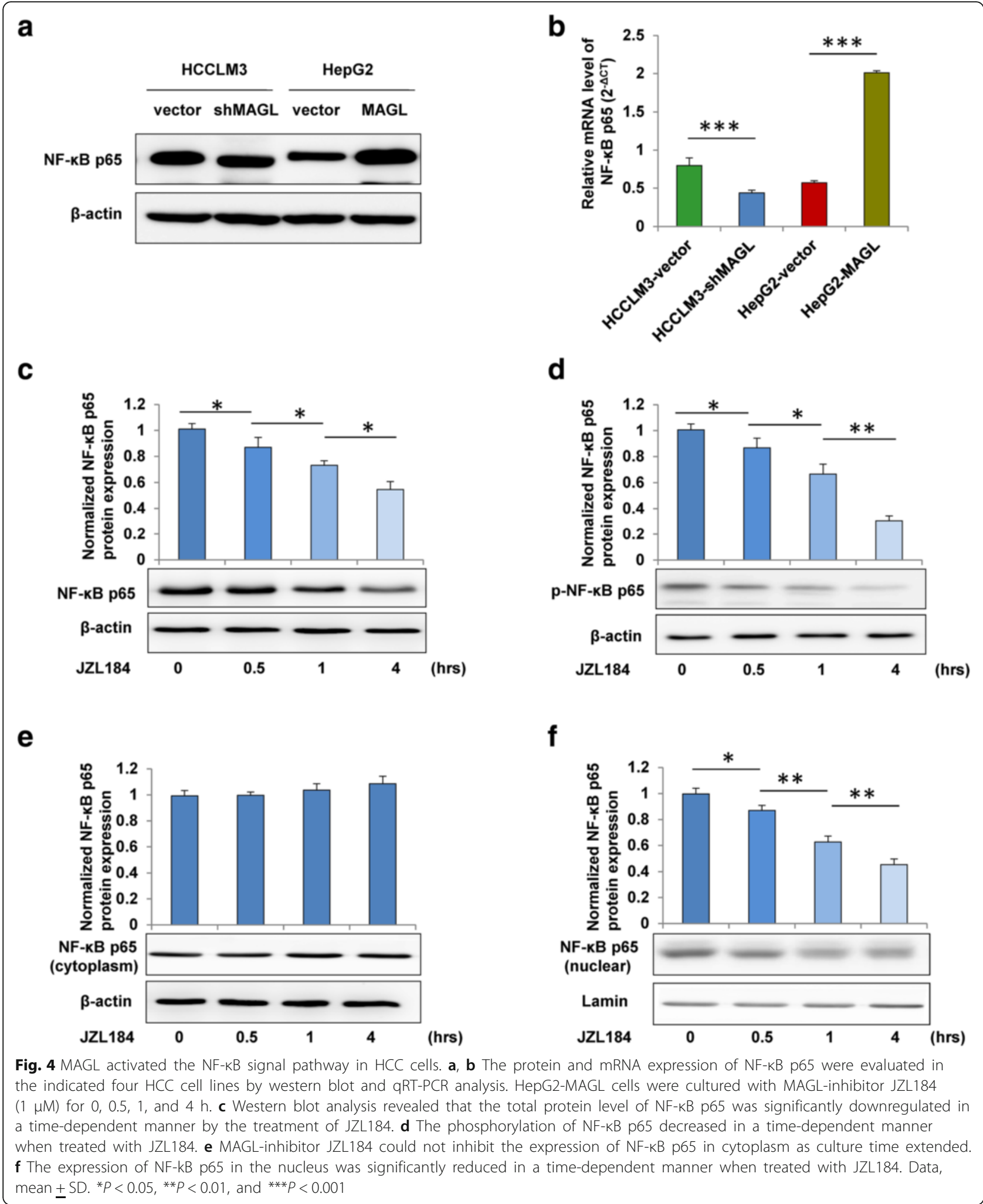

No patient received any preoperative anticancer treatment. Prior patient consent from each participant and ethical approval from the Research Ethics Committee of
Fudan University Shanghai Cancer Center were obtained. The detailed follow-up procedures were described previously $[28,29]$. 
a

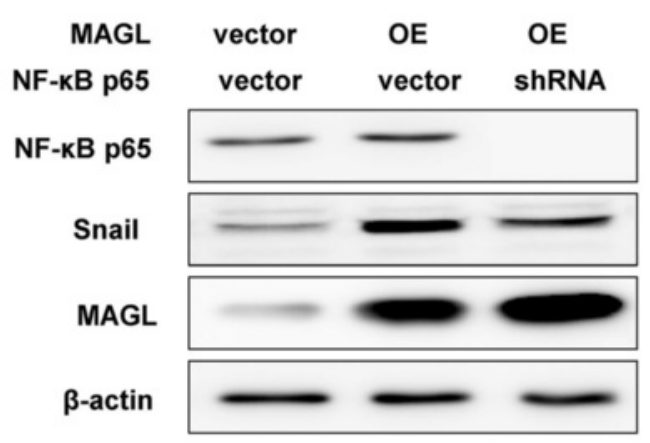

C

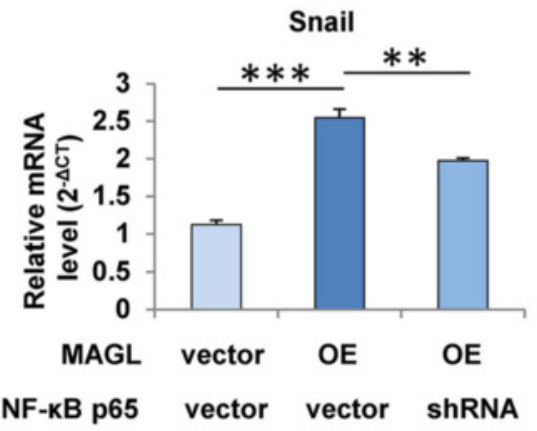

e

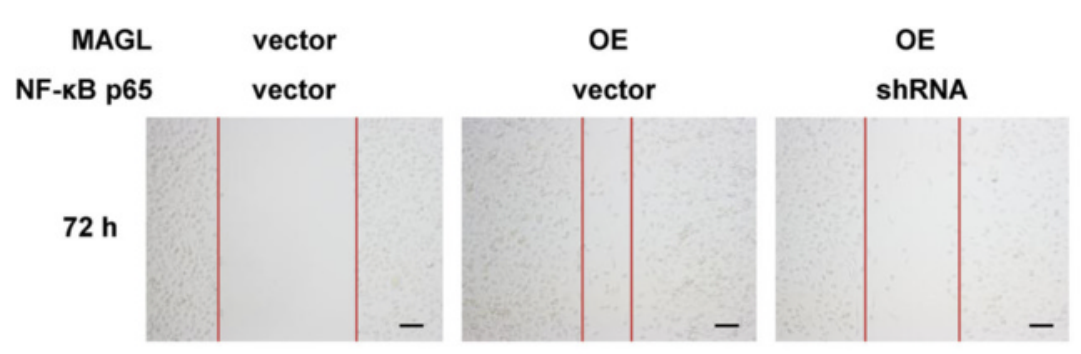

f

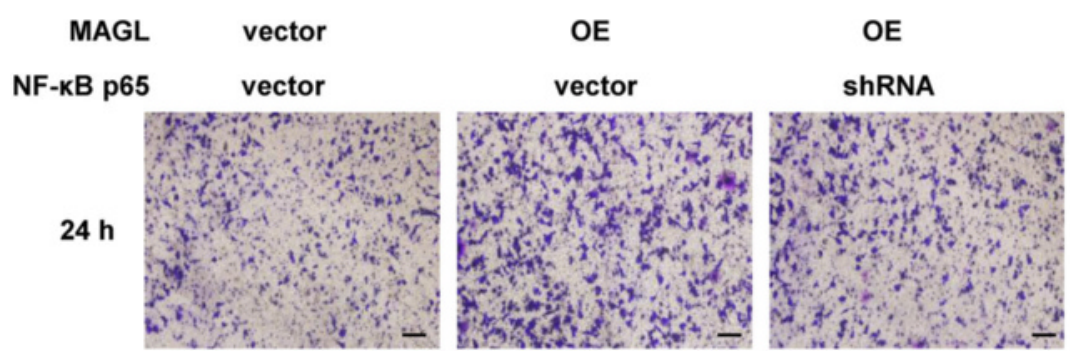

b

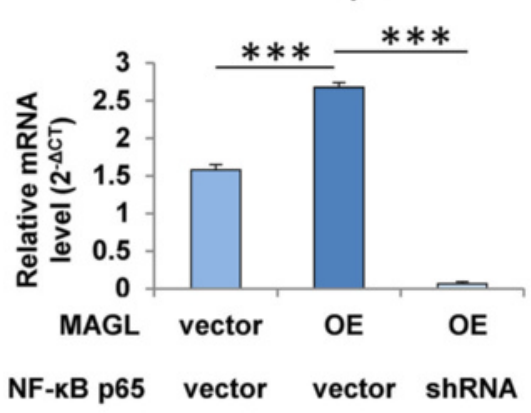

d

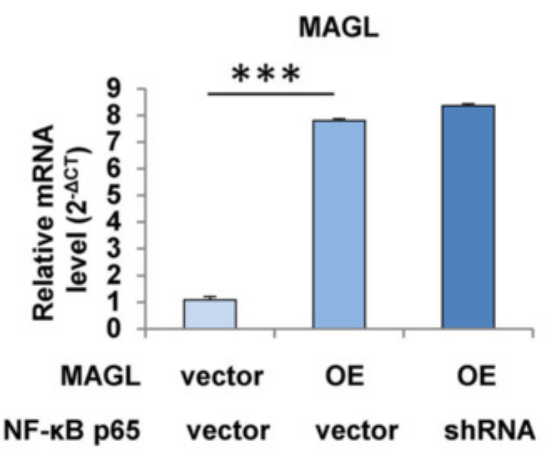

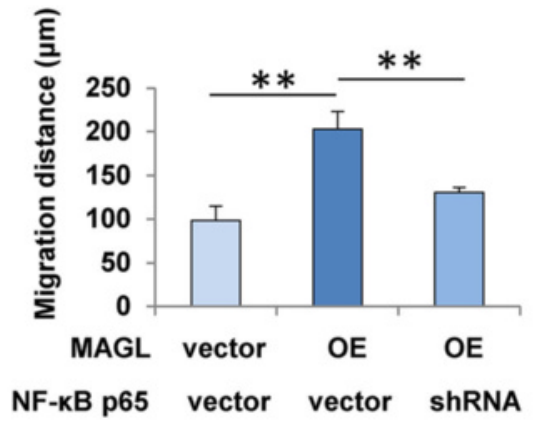

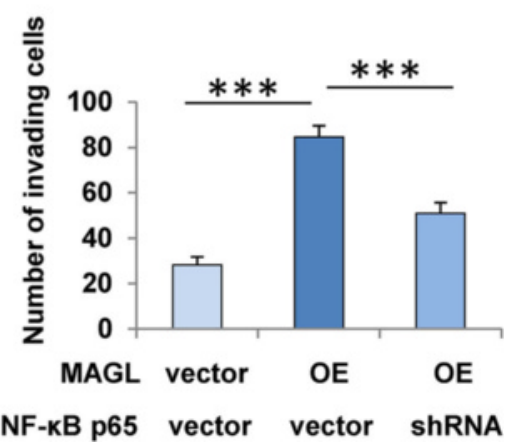

Fig. 5 MAGL facilitates EMT via the NF-KB signaling pathway. a Western blot assay showed the expression of NF-KB p65, Snail, and MAGL in HCC cells with different MAGL expression (HepG2-vector, HepG2-OE). b-d qRT-PCR analysis of NF-KB p65, Snail, and MAGL expression in the indicated cell lines. e Scratch wound assay revealed that the blockade of NF-KB p65 in HepG2 cells by p65-shRNA significantly suppressed MAGL-induced cell migration. $\mathbf{f}$ Transwell Matrigel invasion assay indicated that NF-kB p65-shRNA treatment markedly reversed MAGL-induced invasion. Data, mean \pm SD. ${ }^{* *} P<0.01$ and ${ }^{* * *} P<0.001$. OE overexpression 


\section{Cell lines and morphological observation}

Six HCC cell lines, HepG2 (American Type Culture Collection), Huh7 (Japanese Cancer Research Bank), SMMC7721 (the Second Military Medicine College, Shanghai, China), MHCC97L, MHCC97H, and HCCLM3 (the Liver Cancer Institute of Zhongshan Hospital, Shanghai, China) were used in this study. One normal liver cell line, L0-2 (American Type Culture Collection) served as a control. All cell lines were incubated in high glucose Dulbecco's modified Eagle medium (DMEM; Invitrogen), supplemented with $10 \%$ fetal bovine serum (FBS; Invitrogen) at $37{ }^{\circ} \mathrm{C}$ under $5 \% \mathrm{CO}_{2}$ in humidified incubator. The morphology of HCC cells was assessed by phase microscopy (Leica).

\section{Quantitative real-time PCR and western blot analyses}

RNA isolation, quantitative real-time PCR (qRT-PCR), and western blot analyses were performed as previously described [30-32]. The primers and antibodies used are listed in the Additional file 1: Tables S1 and S2, respectively.

\section{Tissue microarray and immunohistochemistry (IHC) analyses}

Tissue microarrays (TMA) were constructed with the specimens collected from $170 \mathrm{HCC}$ patients. Immunohistochemistry protocols were described in our previous study [33]. The immunoreactive score system (IRS) performed in this study has been described previously $[34,35]$. The antibodies used in this study are listed in the Additional file 1: Table S2. The quantification of MAGL expression in TMA were evaluated by the integrated optical density (IOD) as previously described [36]. The median density of IOD was calculated and used as a cutoff value in subsequent analyses.

\section{Cell transfection}

The short hairpin RNA (shRNA)-mediated stable silencing technique was used to assess the functional role of MAGL in HCC cells as previously described [37]. The designed target sequence for MAGL was cloned into the pLKO.1 TRC cloning vector (Additional file 1: Table S3). Lentiviral particles were constructed through cotransfection of the shRNA plasmid and the lentiviral enveloping and packaging plasmid (pMD2.G and psPAX2) into 293 $\mathrm{T}$ cells. The HCC cells were transfected with the viral particles, and then selected with $2 \mathrm{mg} / \mathrm{ml}$ puromycin (P8833; Sigma-Aldrich).

\section{Cell migration assay}

Cell migration assay was performed by the scratch wound assay. HCC cells were cultured to form a tight cell monolayer, and then wounded with $200-\mu \mathrm{l}$ plastic pipette tip. At 0 and $72 \mathrm{~h}$, the migrating distance of $\mathrm{HCC}$ cells at the wound front were analyzed by an inverted microscope (Leica) for three randomly captured images.

\section{Cell matrigel invasion assay}

Cell invasion assay were assessed using 24-well transwells $(8 \mu \mathrm{m}$ pore size; Corning, USA) precoated with Matrigel (Falcon354480; BD Biosciences, USA). HCC cells placed in the upper chamber were suspended in serum-free medium, and the lower chamber were added with serum-containing medium. After $24 \mathrm{~h}$ of incubation, the cells on the lower surface of the Matrigel membrane were fixed by paraformaldehyde, and then stained with Giemsa. The quantity of cells were counted and photographed at $\times 100$ magnification. All experiments were carried out in triplicate.

\section{Animals and in vivo experiment}

Male athymic BALB/c nude mice (4-6-weeks-old) were obtained from Shanghai Institute of Material Medicine, Chinese Academy of Science, and raised in specific pathogen-free conditions. Animal care and experimental protocols were performed according to the guidelines approved by the Shanghai Medical Experimental Animal Care Commission. Twenty mice were randomly divided into four groups, and $1 \times 10^{7} \mathrm{HCC}$ cells (HepG2-vector, HepG2-MAGL, HCCLM3-vector, and HCCLM3shMAGL) in $0.2 \mathrm{ml}$ normal saline were implanted by subcutaneous injection to construct subcutaneous tumors. Tumor dimensions were measured with vernier calipers after 4 weeks, and then calculated by the formula: tumor volume $=\left(\right.$ length $\times$ width $\left.^{2}\right) / 2$.

\section{Statistical analysis}

Data was analyzed with SPSS 19.0 for Windows (IBM) as previously described [38]. Differences among variables were compared by Pearson's chi-square test or Fisher's exact test. Overall survival (OS) was defined as the interval between surgery and death or between surgery and the last observation point. Time to recurrence (TTR) was defined as the interval between surgery and recurrence. The data of patients experiencing death or alive without recurrence were censored at the date of death or the last follow-up, respectively [39]. The survival and cumulative recurrence rates were performed by the Kaplan-Meier method and calculated by the log-rank test. The Cox proportional hazards regression model was used to carry out univariate and multivariate analysis. All variables might be associated with OS or TTR were subjected to the multivariate Cox analysis with 0.2 level for entry into the model. $P<0.05$ was considered statistically significant. 


\section{Additional file}

Additional file 1: Tables S1, S2. The primers and antibodies used in the study. Table $\mathbf{S 3}$. The sequences of shRNA targeting MAGL and NF-KB p65. Figure S1. Representative images of MAGL immunohistochemic staining. Figure S2. qRT-PCR assay of MAGL mRNA expression in 27 tumor samples. Figure S3. The regulating effects of MAGL on NF-KB p65, $\mathrm{N}$-cadherin, and Snail expression in HCCLM3 cells with different MAGL expression levels. (PDF 303 kb)

\section{Abbreviations}

EMT: Epithelial-mesenchymal transition; HCC: Hepatocellular carcinoma; IOD: Integrated optical density; IRS: Immunoreactive score system; MAGL: Monoacylglycerol lipase; OS: Overall survival; TMA: Tissue microarray; TTR: Time to recurrence

\section{Acknowledgements}

We thank DHZ and SL for the assistance in collecting the patient specimens and data.

\section{Funding}

This study was jointly supported by the National Natural Science Funds of China (No. 81372314; No.81272393) and the Public Health Bureau Youth Foundation of Shanghai (No.20134Y089; No.12ZR1442200). The funders had no role in the study, design, and data collection and analysis, decision to publish, or preparation of the manuscript.

\section{Availability of data and materials}

The datasets during and/or analyzed during the current study are available from the corresponding author on reasonable request.

\section{Authors' contributions}

WPZ, YMZ, JMZ, and XW performed the research and wrote the manuscript. $L W$ revised the manuscript. DHZ and SL conducted the collection of clinical samples and related clinical data. LRW and MW conducted the cell culture and the assessment of cell bio-behaviors. NZ and ZYL conducted western blot, qRT-PCR, and IHC assays. QP and DNM offered professional advices about the whole research. All authors read and approved the final manuscript.

\section{Competing interests}

The authors declare that they have no competing interests.

\section{Consent for publication}

Not applicable.

\section{Ethics approval and consent to participate}

The experiments were approved by the Research Ethics Committee of Fudan University Shanghai Cancer Center and performed in accordance with the relevant guidelines and regulations, and informed consent was obtained from all the subjects.

\section{Author details}

'Department of Hepatic Surgery, Fudan University Shanghai Cancer Center, Shanghai Medical College, Fudan University, Shanghai 200032, People's Republic of China. 'Department of Rheumatology, Xiyuan Hospital, China Academy of Chinese Medical Sciences, 1 Xiyuan Caochang, Haidian District, Beijing 100091, People's Republic of China. 'Liver Cancer Institute, Zhongshan Hospital, Fudan University, Shanghai 200032, People's Republic of China.

Received: 13 October 2016 Accepted: 18 November 2016 Published online: 25 November 2016

\section{References}

1. Torre LA, Bray F, Siegel RL, Ferlay J, Lortet-Tieulent J, Jemal A. Global cancer statistics, 2012. CA Cancer J Clin. 2015;65(2):87-108.

2. Forner A, Llovet JM, Bruix J. Hepatocellular carcinoma. Lancet (London, England). 2012;379(9822):1245-55.
3. Poon D, Anderson BO, Chen LT, Tanaka K, Lau WY, Van Cutsem E, Singh H, Chow WC, Ooi LL, Chow P, et al. Management of hepatocellular carcinoma in Asia: consensus statement from the Asian Oncology Summit 2009. Lancet Oncol. 2009:10(11):1111-8.

4. Kalluri R, Weinberg RA. The basics of epithelial-mesenchymal transition. J Clin Invest. 2009:119(6):1420-8.

5. Thiery JP, Acloque H, Huang RY, Nieto MA. Epithelial-mesenchymal transitions in development and disease. Cell. 2009;139(5):871-90.

6. Thiery JP, Sleeman JP. Complex networks orchestrate epithelialmesenchymal transitions. Nat Rev Mol Cell Biol. 2006;7(2):131-42.

7. Yang J, Weinberg RA. Epithelial-mesenchymal transition: at the crossroads of development and tumor metastasis. Dev Cell. 2008;14(6):818-29.

8. Perl AK, Wilgenbus P, Dahl U, Semb H, Christofori G. A causal role for E-cadherin in the transition from adenoma to carcinoma. Nature. 1998; 392(6672):190-3.

9. Sanchez-Tillo E, Liu Y, de Barrios O, Siles L, Fanlo L, Cuatrecasas M, Darling DS, Dean DC, Castells A, Postigo A. EMT-activating transcription factors in cancer: beyond EMT and tumor invasiveness. Cell Mol Life Sci. 2012;69(20): 3429-56.

10. Muqbil I, Wu J, Aboukameel A, Mohammad RM, Azmi AS. Snail nuclear transport: the gateways regulating epithelial-to-mesenchymal transition? Semin Cancer Biol. 2014;27:39-45.

11. Guo F, Parker Kerrigan BC, Yang D, Hu L, Shmulevich I, Sood AK, Xue F, Zhang W. Post-transcriptional regulatory network of epithelial-tomesenchymal and mesenchymal-to-epithelial transitions. J Hematol Oncol. 2014;7(1):1622.

12. Smith AD. Strategies for modern biomarker and drug development in oncology. J Hematol Oncol. 2014;7(1):1-16.

13. Lou G. Exosomes derived from miR-122-modified adipose tissue-derived MSCs increase chemosensitivity of hepatocellular carcinoma. J Hematol Oncol. 2015;8(1):1-11.

14. Karlsson M, Contreras JA, Hellman U, Tornqvist H, Holm C. CDNA cloning, tissue distribution, and identification of the catalytic triad of monoglyceride lipase. Evolutionary relationship to esterases, lysophospholipases, and haloperoxidases. J Biol Chem. 1997;272(43):27218-23.

15. Bertrand T, Auge F, Houtmann J, Rak A, Vallee F, Mikol V, Berne PF, Michot N, Cheuret D, Hoornaert C, et al. Structural basis for human monoglyceride lipase inhibition. J Mol Biol. 2010;396(3):663-73.

16. Nomura DK, Long JZ, Niessen S, Hoover HS, Ng SW, Cravatt BF. Monoacylglycerol lipase regulates a fatty acid network that promotes cancer pathogenesis. Cell. 2010;140(1):49-61.

17. Nomura DK, Lombardi DP, Chang JW, Niessen S, Ward AM, Long JZ, Hoover $\mathrm{HH}$, Cravatt BF. Monoacylglycerol lipase exerts dual control over endocannabinoid and fatty acid pathways to support prostate cancer. Chem Biol. 2011;18(7):846-56.

18. Polyak K, Weinberg RA. Transitions between epithelial and mesenchymal states: acquisition of malignant and stem cell traits. Nat Rev Cancer. 2009; 9(4):265-73

19. Nieto MA, Cano A. The epithelial-mesenchymal transition under control: global programs to regulate epithelial plasticity. Semin Cancer Biol. 2012; 22(5-6):361-8

20. Huber MA, Azoitei N, Baumann B, Grunert S, Sommer A, Pehamberger H, Kraut N, Beug H, Wirth T. NF-kappaB is essential for epithelial-mesenchymal transition and metastasis in a model of breast cancer progression. J Clin Invest. 2004;114(4):569-81.

21. Julien S, Puig I, Caretti E, Bonaventure J, Nelles L, van Roy F, Dargemont C, de Herreros AG, Bellacosa A, Larue L. Activation of NF-kappaB by Akt upregulates Snail expression and induces epithelium mesenchyme transition. Oncogene. 2007;26(53):7445-56.

22. Yang LX, Gao Q, Shi JY, Wang ZC, Zhang Y, Gao PT, Wang XY, Shi YH, Ke AW Shi GM, et al. Mitogen-activated protein kinase kinase kinase 4 deficiency in intrahepatic cholangiocarcinoma leads to invasive growth and epithelialmesenchymal transition. Hepatology (Baltimore, Md). 2015;62(6):1804-16.

23. Currie E, Schulze A, Zechner R, Walther TC, Farese Jr RV. Cellular fatty acid metabolism and cancer. Cell Metab. 2013;18(2):153-61.

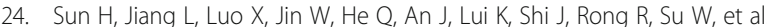
Potential tumor-suppressive role of monoglyceride lipase in human colorectal cancer. Oncogene. 2013;32(2):234-41.

25. Ye L, Zhang B, Seviour EG, Tao KX, Liu XH, Ling Y, Chen JY, Wang GB. Monoacylglycerol lipase (MAGL) knockdown inhibits tumor cells growth in colorectal cancer. Cancer Lett. 2011;307(1):6-17. 
26. Scheel C, Weinberg RA. Phenotypic plasticity and epithelial-mesenchymal transitions in cancer and normal stem cells? Int J Cancer. 2011;129(10):2310-4.

27. Shaul YD, Freinkman E, Comb WC, Cantor JR, Tam WL, Thiru P, Kim D, Kanarek N, Pacold ME, Chen WW, et al. Dihydropyrimidine accumulation is required for the epithelial-mesenchymal transition. Cell. 2014;158(5): 1094-109.

28. Ke AW, Shi GM, Zhou J, Wu FZ, Ding ZB, Hu MY, Xu Y, Song ZJ, Wang ZJ, Wu JC, et al. Role of overexpression of CD151 and/or c-Met in predicting prognosis of hepatocellular carcinoma. Hepatology (Baltimore, Md). 2009; 49(2):491-503.

29. Ma DN, Chai ZT, Zhu XD, Zhang N, Zhan DH, Ye BG, Wang CH, Qin CD, Zhao YM, Zhu WP, et al. MicroRNA-26a suppresses epithelial-mesenchymal transition in human hepatocellular carcinoma by repressing enhancer of zeste homolog 2. J Hematol Oncol. 2016;9:1.

30. Zhao YM, Zhou JM, Wang LR, He HW, Wang XL, Tao ZH, Sun HC, Wu WZ, Fan J, Tang ZY, et al. HIWI is associated with prognosis in patients with hepatocellular carcinoma after curative resection. Cancer. 2012; 118(10):2708-17.

31. Zhu W, Zhan D, Wang L, Ma D, Cheng M, Wang H, Zhao J, Cai Y, Cheng Z. Proteasome inhibitor MG132 potentiates TRAlL-induced apoptosis in gallbladder carcinoma GBC-SD cells via DR5-dependent pathway. Oncol Rep. 2016;36(2):845-52.

32. Chai ZT, Zhu XD, Ao JY, Wang WQ, Gao DM, Kong J, Zhang N, Zhang YY, Ye BG, Ma DN. microRNA-26a suppresses recruitment of macrophages by down-regulating macrophage colony-stimulating factor expression through the PI3K/Akt pathway in hepatocellular carcinoma. J Hematol Oncol. 2015;8(1):1-11.

33. Zhao YM, Wang L, Dai Z, Wang DD, Hei ZY, Zhang N, Fu XT, Wang XL, Zhang SC, Qin LX, et al. Validity of plasma macrophage migration inhibitory factor for diagnosis and prognosis of hepatocellular carcinoma. Int J Cancer. 2011;129(10):2463-72.

34. Remmele W, Stegner HE. [Recommendation for uniform definition of an immunoreactive score (IRS) for immunohistochemical estrogen receptor detection (ER-ICA) in breast cancer tissue]. Der Pathologe. 1987;8(3):138-40.

35. Maacke H, Opitz S, Jost K, Hamdorf W, Henning W, Kruger S, Feller AC, Lopens A, Diedrich K, Schwinger E, et al. Over-expression of wild-type Rad51 correlates with histological grading of invasive ductal breast cancer. Int J Cancer. 2000;88(6):907-13.

36. Zhu XD, Zhang JB, Zhuang PY, Zhu HG, Zhang W, Xiong YQ, Wu WZ, Wang L, Tang ZY, Sun HC. High expression of macrophage colonystimulating factor in peritumoral liver tissue is associated with poor survival after curative resection of hepatocellular carcinoma. J Clin Oncol. 2008;26(16):2707-16.

37. Zhu K, Dai Z, Pan Q, Wang Z, Yang GH, Yu L, Ding ZB, Shi GM, Ke AW, Yang $\mathrm{XR}$, et al. Metadherin promotes hepatocellular carcinoma metastasis through induction of epithelial-mesenchymal transition. Clin Cancer Res. 2011;17(23):7294-302.

38. Zhou ZJ, Dai Z, Zhou SL, Hu ZQ, Chen Q, Zhao YM, Shi YH, Gao Q, Wu WZ, Qiu SJ, et al. HNRNPAB induces epithelial-mesenchymal transition and promotes metastasis of hepatocellular carcinoma by transcriptionally activating SNAIL. Cancer Res. 2014;74(10):2750-62.

39. Llovet JM, Di Bisceglie AM, Bruix J, Kramer BS, Lencioni R, Zhu AX, Sherman M, Schwartz M, Lotze M, Talwalkar J, et al. Design and endpoints of clinical trials in hepatocellular carcinoma. J Natl Cancer Inst. 2008;100(10):698-711.

\section{Submit your next manuscript to BioMed Central and we will help you at every step:}

- We accept pre-submission inquiries

- Our selector tool helps you to find the most relevant journal

- We provide round the clock customer support

- Convenient online submission

- Thorough peer review

- Inclusion in PubMed and all major indexing services

- Maximum visibility for your research

Submit your manuscript at www.biomedcentral.com/submit 